\title{
MÉTODO DE STROUT UTILIZANDO DIFERENTES VELOCIDADES DE CENTRIFUGAÇÃO NO DIAGNÓSTICO DA FASE AGUDA DA DOENÇA DE CHAGAS
}

\author{
Antonio Emanuel e Cleudson Nery de Castro
}

\begin{abstract}
Empregando-se o método de Strout, analisou-se a eficácia de três diferentes velocidades de centrifugação $(19 \mathrm{G}, 165 \mathrm{G}$ e $640 \mathrm{G})$ na avaliação da parasitemia de 20 chagásicos em'fase aguda. Realizaram-se 309 exames nos 20 pacientes, com média de 15 exames para cada caso. Os exames realizados a 19 G evidencia ram a menor eficácia enquanto os realizados a $165 \mathrm{G}$ e $640 \mathrm{G}$ mostraram-se igualmente eficazes.

Palavras chaves: Método de Strout. Doença de Chagas aguda.
\end{abstract}

O diagnóstico da fase aguda da doença de Chagas implica no encontro de tripanossomas no sangue periférico. Entre os procedimentos que se utilizam para detectá-los, rapidamente, o método de Strout ${ }^{4}$, modificado por Flores ${ }^{3}$, é considerado o mais eficaz. Contudo, sendo realizado como foi descrito por aqueles autores, boa parte dos parasitos deixam de ser visualizados. A partir desta observação, procuramos verificar uma maneira mais apropriada de se realizar o método. Este trabalho relata o resultado de nossas observações utilizando centrifugação em três diferentes velocidades.

\section{MATERIAL E MÉTODOS}

De 1980 a 1981, acompanhamos 20 pacientes com forma aguda da doença de Chagas, no Hospital Presidente Médici, DF, todos diagnosticados pelo encontro do tripanossoma no sangue periférico e internados para tratamento clínico. Quinze eram do sexo masculino e cinco do sexo feminino. A idade variou de 1 a 65 anos, com média de 27 anos. Quanto à profissão, 10 eram lavradores e duas eram domésticas; os oito restantes eram menores de idade. Quanto a procedência, 18 eram da Bahia, um de Goiás e um de Minas Gerais.

Empregando-se o método de $\mathrm{Strout}^{4}$, modificado por Flores $^{3}$, avaliamos a parasitemia, seriadamente, em cada um dos pacientes, duas a très vezes por semana, em dias diferentes. Além da clássica centrifugação a $165 \mathrm{G}$, usada por Flores ${ }^{3}$, avaliamos os resultados a $19 \mathrm{G}$ e a $640 \mathrm{G}$. Ao todo estudamos 122 amostras de sangue, com média de seis para cada paciente, tomadas antes e durante o tratamento (Tabela 1). Destas, 71 serviram para estudo comparativo das três diferentes velocidades e em 102 foram analisados somente cientrifugação a $165 \mathrm{G}$ e $640 \mathrm{G}$.

Para cada exame colhiamos, em média, $10 \mathrm{ml}$ de sangue e deixávamos coagular e retrair espontaneamente. Cinco a oito horas após a colheita, separávamos o soro, ao qual deixávamos, propositalmente, um pouco de hemácias, e procedíamos à primeira

Núcleo de Medicina Tropical e Nutriçào, Universidade de Brasilia, 70910 Brasilia, Brasil

Recebido para publicação em 17/08/1983. centrifugação a $19 \mathrm{G}$, por 5 minutos. O sobrenadante de 100 amostras desta primeira rotação era subdividido, em partes iguais, em dois tubos: um era rodado a $165 \mathrm{G}$, durante 10 minutos e o outro a $640 \mathrm{G}$; pelo mesmo tempo; as 22 amostras restantes, após centrifugação a $19 \mathrm{G}$, foram novamente centrifugadas, somente a $165 \mathrm{G}$ ou a $640 \mathrm{G}$. As hemácias facilitavam a focalização ao microscópio e a visualização dos tripanosomas.

Depois de processadas as centrifugações, os sedimentos eram examinados. Ao todo, examinamos 89 sedimentos obtidos a $19 \mathrm{G}: 19$ antes do tratamento e 70 no decorrer dele; 105 obtidos a $165 \mathrm{G}: 20$ antes do tratamento e 85 durante ele; e 115 a $640 \mathrm{G}: 22$ antes do tratamento e 93 na vigência dele (Tabela 1).

Tabela 1 - Número de exames pelo método de Strout, realizados antes e depois de iniciado o tratamento, em três diferentes forças centrifugas

\begin{tabular}{cccc}
\hline Força & \multicolumn{2}{c}{ Número de Exames } & Total \\
\cline { 2 - 3 } centrifuga & Antes & Depois & \\
\hline $19 \mathrm{G}$ & 19 & 70 & 89 \\
$165 \mathrm{G}$ & 20 & 85 & 105 \\
$640 \mathrm{G}$ & 22 & 93 & 115 \\
\hline
\end{tabular}

Os sedimentos examinados foram colocados em lãmina, cobertos com lamínula de $24 \times 32$ mm observados, ao microscópio de luz, com o aumento de $400 x$. Como sedimento do primeiro centrifugado eram examinados 50 campos: 10 nas proximidades de cada ângulo da lamínula e 10 no centro. Com o sedimento dos dois outros centrifugados também se examinava, inicialmente, 50 campos de cada um deles, obedecendo-se à mesma distribuição anteriormente citada. Caso fossem negativos, examinávamos mais 300 campos de cada lâmina.

\section{RESULTADOS:}

Centrifugação $19 \mathrm{G}$ - Antes do tratamento, 12 $(63,1 \%)$ das 19 pesquisas realizadas evidenciaram o T. cruzi, com uma média de 16,5 parasitos por exame (Tabela 2). Durante o tratamento, apenas $15(21,4 \%)$ dos exames realizados continuaram positivos (Tabela $3)$. 
Emanuel A, Castro CN. Método de Strout utilizando diferentes velocidades de centrifugạ̧ão no diagnóstico da fase aguda da doença de Chagas. Revista da Sociedade Brasileira de Medicina Tropical 18: 247-249, Out-Dez, 1985

Tabela 2 - Resultado dos exames realizados pelo método de Strout em 20 pacientes com Chagas agudo, antes do tratamento.

\begin{tabular}{|c|c|c|c|c|c|c|c|c|c|}
\hline \multirow{3}{*}{$\begin{array}{l}\text { No do } \\
\text { caso }\end{array}$} & \multicolumn{6}{|c|}{$\begin{array}{r}\text { Força centrifuga } \\
\qquad 165 \mathrm{G}\end{array}$} & \multicolumn{3}{|c|}{$640 G$} \\
\hline & \multicolumn{2}{|c|}{ Exames } & \multirow[t]{2}{*}{$N{ }^{o}$ de } & \multicolumn{2}{|c|}{ Exames } & No de & \multicolumn{2}{|c|}{ Exames } & \multirow{2}{*}{$\begin{array}{c}\text { No de } \\
\text { Parasitos }\end{array}$} \\
\hline & Realizados & Positivos & & Realizados & Positivos & Parasitos & Realizados & Positivos & \\
\hline 2 & & & & & & & 1 & 1 & 35 \\
\hline 3 & 1 & 0 & & 1 & 1 & 17 & 1 & 1 & 45 \\
\hline 4 & & & & & & & 1 & 1 & 17 \\
\hline 5 & 1 & 0 & & 1 & 1 & 30 & 1 & 1 & 40 \\
\hline 6 & 1 & 0 & & 1 & 0 & & 1 & 1 & 4 \\
\hline 7 & & & & & & & 1 & 1 & 1 \\
\hline 8 & 1 & 1 & 1 & 1 & 1 & 6 & 1 & 1 & 3 \\
\hline 9 & 2 & 1 & 1 & 1 & 0 & & 2 & 2 & 3 \\
\hline 10 & 1 & 1 & 13 & 2 & 2 & 242 & 1 & 1 & 62 \\
\hline 11 & 1 & 0 & & 2 & 1 & 1 & 1 & 0 & \\
\hline 12 & 1 & 0 & & 1 & 1 & 4 & 1 & 1 & 1 \\
\hline 13 & 1 & 1 & 13 & 1 & 1 & 60 & 1 & 1 & 66 \\
\hline 14 & 1 & 1 & 4 & 1 & 1 & 11 & 1 & 1 & 88 \\
\hline 15 & 1 & 1 & 76 & 1 & 1 & 104 & 1 & 1 & 48 \\
\hline 16 & 2 & 2 & 7 & 2 & 2 & 9 & 2 & 2 & 21 \\
\hline 17 & 1 & 1 & 3 & 1 & 1 & 11 & 1 & 1 & 3 \\
\hline 18 & 1 & 1 & 75 & 1 & 1 & 25 & 1 & 1 & 32 \\
\hline 19 & 2 & 1 & 1 & 2 & 2 & 7 & 2 & 2 & 2 \\
\hline 20 & 1 & 1 & 4 & 1 & 1 & 2 & 1 & 1 & 4 \\
\hline Total & 19 & $12(63,1 \%)$ & 198 & 20 & $17(85 \%)$ & 529 & 22 & $21(95,4 \%)$ & 475 \\
\hline
\end{tabular}

Tabela 3 - Resultado dos exames feitos pelo método de Strout em 20 pacientes com Chagas agudo, após inicio do tratamento.

Força centifuga

\begin{tabular}{|c|c|c|c|c|c|c|c|c|c|}
\hline & & $19 \mathrm{G}$ & & & $165 G$ & & & $640 \mathrm{G}$ & \\
\hline No do & $E x c$ & mes & $N^{o} \mathrm{de}$ & Exa & mes & No de & Exa & mes & No de \\
\hline Caso & Realizados & Positivos & Parasitos & Realizados & Positivos & Parasitos & Realizados & Positivos & Parasitos \\
\hline 1 & 2 & 0 & & 5 & 1 & 36 & 6 & 1 & 24 \\
\hline 2 & 4 & 1 & 4 & 10 & 4 & 9 & 10 & 7 & 21 \\
\hline 3 & 2 & 0 & & 7 & 5 & 19 & 8 & 5 & 33 \\
\hline 4 & & & & 1 & 1 & 8 & 2 & 1 & 4 \\
\hline 5 & & & & 1 & 0 & & 1 & 0 & \\
\hline 6 & 2 & 0 & & 2 & 0 & & 2 & 1 & 2 \\
\hline 7 & & & & 1 & 0 & & 3 & 0 & \\
\hline 8 & 7 & 3 & 10 & 9 & 2 & 11 & 9 & 3 & 7 \\
\hline 9 & 2 & 0 & & 2 & 0 & & 2 & 0 & \\
\hline 10 & 7 & 4 & 131 & 7 & 4 & 273 & 7 & 4 & 209 \\
\hline 11 & 3 & 0 & & 2 & 0 & & 2 & 0 & \\
\hline 12 & 5 & 0 & & 6 & 2 & 5 & 6 & 2 & 7 \\
\hline 13 & 5 & 2 & 11 & 5 & 2 & 27 & 5 & 2 & 37 \\
\hline 14 & 7 & 0 & & 7 & 2 & 6 & 6 & 3 & 17 \\
\hline 15 & 6 & 3 & 56 & 6 & 3 & 103 & 6 & 3 & 88 \\
\hline 16 & 5 & 1 & 1 & 5 & 1 & 1 & 5 & 1 & 1 \\
\hline 17 & 3 & 0 & & 3 & 0 & & 3 & 0 & \\
\hline 18 & 3 & 1 & 2 & & & & 3 & 1 & 14 \\
\hline 19 & 4 & 0 & & 4 & 0 & & 4 & 0 & \\
\hline 20 & 3 & 0 & & 3 & 0 & & 3 & 0 & \\
\hline Total & 70 & $15(21,4 \%)$ & 215 & 86 & $27(31,3 \%)$ & 498 & 93 & $34(36,5 \%)$ & 464 \\
\hline
\end{tabular}


Emanuel A, Castro CN. Método de Strout utilizando diferentes velocidades de centrifugação no diagnóstico da fase aguda da doença de Chagas. Revista da Sociedade Brasileira de Medicina Tropical 18: 247-249, Out-Dez, 1985

Centrifugação a $165 G$ - Os parasitos foram encontrados em $17(85,0 \%)$ dos 20 exames realizados antes do tratamento (Tabela 2 ) e em $27(31,3 \%)$ dos 86 feitos depois dele (Tabela 3 ). Nos 17 exames positivos antes do tratamento encontrou-se uma média de 31,1 tripanossomas por exame (Tabela 2).

Centrifugação a $640 \mathrm{G}$-Dos 22 exames realizados antes do tratamento, $21(95,4 \%)$ foram positivos, com média de 22,6 parasitos por exame (Tabela 2). Dos 93 exames realizados após o tratamento 34 $(36,5 \%)$ ainda permaneceram positivos (Tabela 3 ).

Comparação dos resultados nas três velocidades de centrifugação - Das 71 amostras de soro examinadas nas três velocidades de centrifugação, 23 $(32,3 \%)$ foram positivos a $19 \mathrm{G}, 31(43,6 \%)$ a $165 \mathrm{G}$ e $36(50,7 \%)$ a $640 \mathrm{G}$ (Tabela 4). Das 102 examinadas a $165 \mathrm{G}$ e $640 \mathrm{G}$, foram positivas $42(41,1 \%)$ e 50 $(49,0)$, respectivamente (Tabela 5).

Em cinco casos, considerados negativos ao se examinar os 50 campos iniciais das três velocidades encontramos 1 a 2 parasitos ao examinar os 300 campos restantes.

Em dois exames a parasitemia só foi detectada no sedimento obtido a $19 \mathrm{G}$, e em 15 oportunidades foi negativa nesta velocidade e positiva nas duas outras.

Tabela 4 - Resultado do método de Strout em 71 amostras de soro examinadas após diferentes centrifugaçōes.

\begin{tabular}{cc}
\hline Força centrifuga & Positividade \\
\hline $19 \mathrm{G}$ & $23(32,3 \%)$ \\
$165 \mathrm{G}$ & $31(43,6 \%)$ \\
$640 \mathrm{G}$ & $36(50,7 \%)$ \\
\hline
\end{tabular}

Tabela 5-Resultados do método de Strout em 102 amostras de soro examinadas a $165 \mathrm{G}$ e $640 \mathrm{G}$.

\begin{tabular}{cc}
\hline Força centrifuga & Positividade \\
\hline $165 \mathrm{G}$ & $42(41,1 \%)$ \\
$640 \mathrm{G}$ & $50(49,0 \%)$ \\
\hline
\end{tabular}

\section{COMENTÁRIOS}

O exame do creme leucocitário é o método mais freqüentemente utilizado para a pesquisa direta do $T$. crusi em casos agudos de doença de Chagas e aquele em que se obtém maior grau de positividade. Entretanto, o método de Strout ${ }^{4}$, modificado por Flores ${ }^{3}$ mostrou-se superior aos demais quando realizado comparativamente ${ }^{2}$. Efetuando-se uma velocidade "lenta" a $165 \mathrm{G}$ por 3 minutos e, em seguida, uma velocidade rápida do sobrenadante a $640 \mathrm{G}$, por $1 \mathrm{mi}$ nuto, como recomendado pelos autores, comprovamos haver sedimentação de grande número de parasitos na centrifugação inicial. Como eles examinavam apenas o sedimento da segunda centrifugação, por certo, perdiam a chance de detectar boa parte dos parasitose, até mesmo, de não encontrá-los.

Os exames realizados no sedimento obtido a $19 \mathrm{G}$ foram os que evidenciaram menor índice de positividade, menor número de parasitos e negativação mais precoce. Entretanto, em duas oportunidades foi o único meio de se comprovar a existência de parasitismo.

As pesquisas realizadas após centrifugação a $165 \mathrm{G}$ e $640 \mathrm{G}$, não só elevaram o número de exames positivos, como apresentaram maior média de parasitos por exame.

Em duas oportunidades observamos aspecto interessante: a recentrifugação do sobrenadante obtido a $165 \mathrm{G}$ a $640 \mathrm{G}$ e vice-versa, ainda evidenciou parasitos no sedimento de cada uma delas. Isto mostra que ambas as centrifugações, realizadas em 10 minutos, são insuficientes para sedimentar os tripanossomas existentes no soro, pelo menos em alguns casos, o que seria ideal. Vale ressaltar que o número de parasitos encontrados neste terceiro sedimento foi sempre bem pequeno, quando comparado com o segundo.

Como dissemos, o método de Strout é o mais eficaz para a identificação de tripanossomas no sangue periférico, em pacientes com a forma aguda da doença de Chagas. A melhor maneira de proceder a sua realização nos parece ser como agora descrevemos: uma centrifugação realmente lenta, a $19 \mathrm{G}$ durante 5 minutos. Esta centrifugação separa a maior parte das hemácias e perde menos parasitos do que a centrifugação a $165 \mathrm{G}$. Após a centrifugação inicial de $19 \mathrm{G}$, então centrifugamos o sobrenadante a $165 \mathrm{G}$ ou $640 \mathrm{G}$ por 10 minutos e examinamos o sedimento. Desse modo obtivemos $100 \%$ de possibilidade nos casos examinados, enquanto Cedillos e cols ${ }^{1}$ obtiveram apenas $70 \%$ empregando a técnica clássica.

\section{SUMMARY}

Using Strout's method we determined the efficacy of three different centrifuge speeds $(19 \mathrm{G}, 165 \mathrm{G}$ and $640 \mathrm{G}$ ) to evaluate the level of parasitemia in 20 patients with acute Chagas' disease. The technique was performed 309 times an average of 15 tests for each patient. The highest centrifuge speed was most efficacious in detecting circulating trypanosomes. disease.

Key words: Strout's method. Acute Chagas'

\section{REFERÊNCIAS BIBLIOGRÁFICAS}

1. Cedillos RA, Dimas D, Hernandez AY. Blood concentration method in the diagnosis of Chagas' disease. Revista Latino Americana de Microbiologia 12: 200203, 1970

2. Cerisola, JA, Rohwedder, R, Segura, EL, Prado, CE, Alvarez M, Martini GJW. El xenodiagnóstico. Ministério de Bien Estar Social. Bueno Aires, outubro 1974.

3. Flores MA, Trefos A, Paudes AR, Ramos AY. El método de concentración de Strout en el diagnóstico de la fase aguda de la enfermedad de Chagas. Boletin Chileno de Parasitología 21: 38-39, 1966.

4. Strout RG. A method for concentrating hemoflagellates. Journal of Parasitology 48: 100, 1962. 